\title{
Efeito da adição de inulina em geleia de abacaxi: análise físico-química e sensorial entre escolares
}

Effect of inulin in pineapple jam: physicochemical and sensory analysis among school children

\author{
Kétlin Ariane Santos* \\ Priscila Naiverth Faix* \\ Elisvânia Freitas dos Santos* * \\ Maria Raquel Manhani*** \\ Érica Caroline da Silva**** \\ Daiana Novello*****
}

\begin{abstract}
Resumo
O presente estudo objetivou avaliar a aceitabilidade sensorial de formulações de geleia de abacaxi tradicional e com adição de inulina entre crianças com idade escolar. Também, determinar a composição físico-química do produto tradicional e daquele com maior teor de inulina e aceitação semelhante ao padrão. Foram elaboradas as seguintes formulações da geleia de abacaxi: F1 (padrão) e as demais com adição de 4\% (F2), 8\% (F3), 12\% (F4) e 16\% (F5) de inulina. Participaram da avaliação sensorial 60 provadores não treinados, de ambos os gêneros, com idade entre 7 e 10 anos. Foram avaliados os atributos aparência, aroma, sabor, textura e cor, bem como a aceitação global e intenção de compra. Nas análises físico-químicas foram determinados o teor de umidade, cinzas, proteínas, lipídios, carboidratos, fibra alimentar e valor calórico. As amostras não apresentaram diferença significativa entre si, em nenhum dos atributos avaliados, demonstrando boa aceitação sensorial pelos provadores. Na análise físico-química, foram observados maiores teores de carboidratos e calorias em F1 comparado a F5. Não houve diferença significativa entre os conteúdos de cinzas, proteínas e lipídeos em ambas as formulações. Maior teor de umidade e fibra alimentar foi encontrado em F5. A elaboração dos produtos permitiu comprovar que um nível de adição de até $16 \%$ de inulina em geleia de abacaxi foi bem aceito pelos provadores, obtendo-se aceitação sensorial semelhante ao produto padrão, com boas expectativas de comercialização e melhora na composição nutricional do alimento.
\end{abstract}

Palavras-chave: Alimento Funcional. Frutas. Criança.

\begin{abstract}
The present study aimed to evaluate the sensory acceptability of traditional formulations pineapple jam of inulin additions among school children. We also intended to determine the physicochemical composition of the traditional product and that having a higher amount of inulin and acceptance similar to standard. The following pineapple jam formulations were developed: F1 (standard) and the other ones with 4\% (F2), 8\% (F3), 12\% (F4) and 16\% (F5) of additional inulin. Sixty non trained tasters, both genders, aged from 7 to 10 years were invited to participate in sensory evaluation. The attributes of appearance, aroma, taste, texture and color were evaluated, and also the overall acceptance and purchase intent. On physicochemical analysis, moisture, ash, proteins, lipids, carbohydrates, dietary fiber and caloric value content were determined. The samples did not show substantial differences among them in none of the evaluated attributes, and the tasters showed great sensory acceptance. Comparing F1 with F5 in the physicochemical analysis, we saw F1 presented higher carbohydrate content than F5. There were no substantial differences among crude ash, proteins and lipids in both formulations. F5 presented the highest moisture content and dietary fiber amount. Products elaboration allowed us to prove that by adding up to $16 \%$ of inulin in pineapple jam, the tasters had a great sensory acceptance, similar to that to the standard product, with good marketing expectations and improvements in the food nutritional composition.
\end{abstract}

Keywords: Functional Food. Fruits. Child.

DOI: 10.15343/0104-7809.20143803286295

* Universidade Estadual do Centro-Oeste, Guarapuava-PR, Brasil. E-mail: ketlin_ariane@hotmail.com; priscila343@hotmail.com

** Universidade Federal de Mato Grosso do Sul, Campo Grande-MS, Brasil. E-mail: elisvania@gmail.com

*** Universidade São Judas Tadeu, São Paulo-SP, Brasil. E-mail: rmanhani@yahoo.com.br

**** Universidade Federal de Mato Grosso do Sul, Campo Grande-MS, Brasil. E-mail: ericacarols@yahoo.com.br

***** Universidade Estadual do Centro-Oeste, Guarapuava-PR, Brasil. E-mail: nutridai@gmail.com

As autoras declaram não haver conflitos de interesse. 


\section{INTRODUC̣ÃO}

A fase escolar de uma criança é compreendida dos 7 aos 10 anos $^{1}$. Nesse período, a dieta alimentar é marcada por alto consumo de produtos industrializados, ricos em gordura e açúcar e baixo teor de fibras ${ }^{2}$. Esse tipo de consumo alimentar torna-se preocupante, uma vez que é nesse período que os hábitos alimentares são formados e persistem durante toda a vida, podendo levar ao aumento do risco de patologias futuras, como a obesidade, diabetes mellitus, hipertensão arterial, entre outras ${ }^{3}$.

$\mathrm{Na}$ tentativa de melhorar a qualidade nutricional dos alimentos comumente consumidos pelas crianças, novas pesquisas, juntamente com a indústria alimentícia, vêm surgindo para o enriquecimento nutricional dos produtos. Uma estratégia muito utilizada para conferir nutrientes aos alimentos é feita por meio da adição de novos ingredientes em produtos. Dentre eles se destaca a inulina, que vem sendo utilizada em diversos produtos, como bolos ${ }^{4}$ e bebidas ${ }^{5}$, obtendo-se bons resultados de aceitabilidade.

A inulina é uma fibra solúvel que chega praticamente intacta ao cólon, servindo de substrato às bactérias benéficas presentes no trato gastrointestinal. Sua obtenção é feita pela extração das raízes de chicória (Cichorium intybus L.). Entre suas características, o fato de não alterar o sabor nem o aroma do produto permite sua ampla utilização na indústria de alimentos $^{6}$. No Brasil, a Agência Nacional de Vigilância Sanitária (ANVISA) reconhece a inulina como um alimento funcional e regulamenta sua utilização em alimentos. Recomenda-se um teor mínimo por porção no produto pronto de $3 \mathrm{~g}$ de inulina e o máximo tolerável não deve ultrapassar $30 \mathrm{~g}^{7-10}$.

A geleia de frutas é um produto bastante consumido por crianças e, por se tratar de um alimento doce, é muito consumido nessa faixa etária. Porém, para sua fabricação, é necessária uma grande quantidade de sacarose, que, em excesso, eleva o risco de desenvolvimento de doenças crônicas não transmissíveis. Dessa forma, deve-se promover a redução no consumo de açúcar por crianças, dando preferência a fibras, vitaminas e minerais encontrados em hortaliças e frutas ${ }^{2}$. Assim, a utilização de ingredientes que apresentem um melhor valor nutricional em geleias torna-se uma estratégia útil para um melhor consumo alimentar. Uma fruta muito utilizada para a fabricação de geleias é o abacaxi. Esse alimento possui um ótimo perfil nutricional, sendo composto por carboidratos, proteínas e lipídeos, além de fibras, vitaminas (tiamina, riboflavina e ácido ascórbico), minerais (cálcio, magnésio, manganês, fósforo, ferro, potássio, cobre, zinco) ${ }^{11}$, nutrientes necessários para o crescimento e desenvolvimento adequado das crianças.

Visando ao sucesso na elaboração e comercialização de novos alimentos, tornam-se necessárias avaliações periódicas nos produtos, principalmente aquelas relacionadas aos aspectos sensoriais. Por meio desse processo, há a possibilidade de intervenção para melhoramento, obtendo-se, assim, maior qualidade do produto final ${ }^{12}$. Ferramentas como a análise sensorial são ainda mais indispensáveis quando os produtos alimentícios estão direcionados ao público infantil. Existem inúmeros alimentos destinados a esse público, sendo que as crianças realizam as compras sozinhas, sobretudo no ambiente escolar. As decisões alimentares são tomadas, muitas vezes, de acordo com influências diversas e, dessa forma, sua opinião deve ser valorizada e analisada ${ }^{13}$. Diante do exposto, o objetivo desse trabalho foi avaliar a aceitabilidade sensorial de formulações de geleia de abacaxi tradicional e com adição de inulina, entre crianças com idade escolar. Também, determinar a composição físico-química do produto tradicional e daquele com maior teor de inulina e aceitação semelhante ao padrão.

\section{MÉTODO}

\section{Aquisição da matéria-prima}

Os produtos foram adquiridos em supermercados do município de Guarapuava-PR, Brasil, e a inulina foi doada por empresas nacionais parceiras. Foram utilizadas para a pesquisa abacaxis do tipo pérola, com melhor aspecto visual, sendo: cor amarela uniforme, podendo conter pequenas manchas amareladas, com tamanhos semelhantes, superfície lisa sem imperfeições e livres de injúrias. 


\section{Formulações}

Foram elaboradas cinco formulações de geleia de abacaxi, sendo: $F 1$ padrão $(0 \%)$ e as demais com adição de 4,0\% (F2), 8,0\% (F3), $12,0 \%$ (F4) e 16,0\% (F5) de inulina. Esses ní- veis de adição foram definidos a partir dos testes sensoriais preliminares realizados com o produto. Na Tabela 1, podem ser verificadas as formulações das geleias com adição de inulina.

Tabela 1. Ingredientes das formulações das geleias de abacaxi com adição de inulina. Guarapuava-PR, 2013

\begin{tabular}{lccccc}
\hline Ingredientes & F1 & F2 & F3 & F4 & F5 \\
\hline Suco de abacaxi (\%) & 83,0 & 83,0 & 83,0 & 83,0 & 83,0 \\
Açúcar refinado (\%) & 16,0 & 12,0 & 8,0 & 4,0 & 0,0 \\
Suco de limão (\%) & 1,9 & 1,9 & 1,9 & 1,9 & 1,9 \\
Inulina em pó (\%) & 0,0 & 4,0 & 8,0 & 12,0 & 16,0 \\
\hline
\end{tabular}

As formulações foram preparadas, individualmente, no Laboratório de Técnica Dietética do Departamento de Nutrição da Universidade Estadual do Centro-Oeste, Guarapuava-PR, Brasil.

A pesquisa foi conduzida entre março e outubro de 2013.

Inicialmente, as coroas dos abacaxis foram retiradas e descartadas. A fruta foi higienizada em água corrente e mantida em solução de água clorada por 15 minutos. Em seguida, após retirada sua casca, a fruta foi picada em cubos, com auxílio de uma faca. O conteúdo foi triturado em liquidificador doméstico para obtenção do suco, que foi coado em equipamento próprio. Após, o suco foi coccionado à temperatura média de $180{ }^{\circ} \mathrm{C}$, mexendo-se sempre, e, em seguida, foi adicionado o suco de limão. Por fim, o açúcar e/ou inulina (conforme Tabela 1) foram adicionados à preparação, sendo cozidos por mais 30 minutos. Após esse processo, as formulações foram dispostas em potes plásticos, hermeticamente fechados, e levados a refrigeração $\left(8^{\circ} \mathrm{C}\right)$ por 6 horas.

\section{Análise sensorial}

Participaram da pesquisa 60 provadores não treinados, sendo crianças devidamente matriculadas em uma Escola Municipal de Guarapuava-PR, de ambos os gêneros, com idades entre 7 e 10 anos.

Os produtos foram submetidos a uma análise sensorial, em uma sala própria da escola, sendo avaliado um aluno por vez. Cada prova foi feita em cabines individuais, do tipo urna, onde o provador foi auxiliado pelas pesquisadoras treinadas para não influenciar o preenchimento das respos- tas. O julgamento sensorial avaliou os atributos de aparência, aroma, sabor, textura e cor. Os provadores analisaram a aceitação das amostras por meio de uma escala hedônica facial estruturada mista de 7 pontos, variando de 1 ("Muito ruim") a 7 ("Muito bom"), adaptada de Resurreccion" ${ }^{14}$. Foram aplicadas, também, questões de aceitação global e intenção de compra analisadas por meio de uma escala hedônica estruturada mista de 5 pontos ( 1 "desgostei muito" / "não compraria" a 5 "gostei muito" / "compraria com certeza"), como sugerido por Minim ${ }^{9}$.

Cada julgador recebeu uma porção de cada amostra (aproximadamente 15 g) em copos plásticos descartáveis brancos, codificados com números de três dígitos, de forma casualizada e balanceada, acompanhados de colheres descartáveis e um copo de água. As formulações foram oferecidas aos julgadores de forma monádica sequencial.

\section{Índice de aceitabilidade (IA)}

O cálculo do índice de aceitabilidade das cinco formulações foi realizado segundo a fórmula: IA $(\%)=A$ x 100/B (A = nota média obtida para o produto; $\mathrm{B}=$ nota máxima dada ao produto $)^{15}$.

\section{Composição físico-química}

As análises físico-químicas foram realizadas no Laboratório de Análise de Alimentos do Departamento e Engenharia de Alimentos da Universidade Estadual do Centro-Oeste, Guarapuava-PR, e no Laboratório de Bromatologia e Composição de Alimentos da Universidade São Judas Tadeu, São Paulo-SP. 
As seguintes determinações foram realizadas, em triplicata, na formulação padrão e naquela com maior teor de inulina e com aceitação sensorial semelhante à padrão: Umidade: foi determinada em estufa a $105{ }^{\circ} \mathrm{C}$ até o peso constante; Cinzas: foram analisadas em mufla $\left(550{ }^{\circ} \mathrm{C}\right)$; Proteínas: foram avaliadas com base no teor de nitrogênio total da amostra, pelo método Kjeldahl, determinado ao nível semimicro. Utilizou-se o fator de conversão de nitrogênio para proteína de 6,256 ; Lipídios totais: utilizou-se o método de extração a frio ${ }^{17}$; Fibra alimentar: foi realizado o cálculo teórico das formulações por meio do programa Avanutri ${ }^{\circledR 18}$; Carboidratos: a determinação de carboidratos dos produtos foi realizada por meio de cálculo teórico (por diferença) nos resultados das triplicatas, conforme a fórmula: \% Carboidratos $=100-(\%$ umidade $+\%$ proteína $+\%$ lipídios + $\%$ cinzas + \% fibra alimentar); Valor calórico: o total de calorias (kcal) foi calculado utilizando os seguintes valores: lipídios $(8,37 \mathrm{kcal} / \mathrm{g})$, proteína $(3,87 \mathrm{kcal} / \mathrm{g})$ e carboidratos $(4,11 \mathrm{kcal} / \mathrm{g})^{19}$. Para a inulina, considerou-se o valor de 1,5 kcal/g20.

\section{Determinação do Valor Diário de Referência (VD)}

O VD foi calculado em relação a $20 \mathrm{~g}$ da amostra, com base nos valores preconizados para crianças de 7 a 10 anos $^{21}$. Os nutrientes foram avaliados pelo cálculo médio dos provadores, resultando em: 2.003,86 kcal/dia, 273,06 g de carboidratos, 69,52 g de proteínas, 73,58 g de lipídios e 13,56 g de fibra alimentar.

\section{Questões éticas}

Esse trabalho foi aprovado por Comitê de Ética em Pesquisa, sob parecer consubstanciado n 49549/2012. Como critérios de exclusão foram considerados os seguintes fatores: possuir alergia a algum ingrediente utilizado na elaboração da geleia de abacaxi, não ser aluno da escola em questão ou não entregar o Termo de Consentimento Livre e Esclarecido (TCLE) assinado pelo responsável legal.

\section{Análise estatística}

Os dados foram analisados com auxílio do software Statgraphics Plus ${ }^{\circledR}$, versão 5.1, por meio da análise de variância (ANOVA). A comparação de médias foi realizada pelo teste de Tukey e t de student, com nível de 5\% de significância.

\section{RESULTADOS E DISCUSSÃO}

\section{Análise Sensorial}

Por meio da Tabela 2, pode-se verificar o resultado da avaliação sensorial das geleias de abacaxi padrão e daqueles com adição de inulina.

Tabela 2. Médias do teste sensorial afetivo e de intenção de compra realizados para as formulações de geleia de abacaxi adicionadas de inulina. Guarapuava-PR, 2013

\begin{tabular}{lccccc}
\hline Atributos & $\begin{array}{c}\text { F1 } \\
\text { Média } \pm \mathbf{E P M}\end{array}$ & $\begin{array}{c}\text { F2 } \\
\text { Média } \pm \mathbf{E P M}\end{array}$ & $\begin{array}{c}\text { F3 } \\
\text { Média } \pm \mathbf{E P M}\end{array}$ & $\begin{array}{c}\text { F4 } \\
\text { Média } \pm \text { EPM }\end{array}$ & $\begin{array}{c}\text { F5 } \\
\text { Média } \pm \text { EPM }\end{array}$ \\
\hline Aparência & $5,66 \pm 0,14^{\mathrm{a}}$ & $5,64 \pm 0,14^{\mathrm{a}}$ & $5,46 \pm 0,14^{\mathrm{a}}$ & $5,88 \pm 0,14^{\mathrm{a}}$ & $5,70 \pm 0,14^{\mathrm{a}}$ \\
Aroma & $6,00 \pm 0,14^{\mathrm{a}}$ & $5,92 \pm 0,13^{\mathrm{a}}$ & $5,74 \pm 0,13^{\mathrm{a}}$ & $5,75 \pm 0,14^{\mathrm{a}}$ & $6,02 \pm 0,13^{\mathrm{a}}$ \\
Sabor & $6,05 \pm 0,12^{\mathrm{a}}$ & $5,96 \pm 0,15^{\mathrm{a}}$ & $6,03 \pm 0,13^{\mathrm{a}}$ & $6,0 \pm 0,13^{\mathrm{a}}$ & $5,88 \pm 0,14^{\mathrm{a}}$ \\
Cor & $5,91 \pm 0,13^{\mathrm{a}}$ & $5,84 \pm 0,14^{\mathrm{a}}$ & $6,02 \pm 0,13^{\mathrm{a}}$ & $5,77 \pm 0,14^{\mathrm{a}}$ & $6,02 \pm 0,13^{\mathrm{a}}$ \\
Textura & $5,84 \pm 0,14^{\mathrm{a}}$ & $5,70 \pm 0,13^{\mathrm{a}}$ & $5,74 \pm 0,13^{\mathrm{a}}$ & $5,89 \pm 0,14^{\mathrm{a}}$ & $5,75 \pm 0,16^{\mathrm{a}}$ \\
Aceitação Global & $4,18 \pm 0,13^{\mathrm{a}}$ & $4,28 \pm 0,10^{\mathrm{a}}$ & $4,22 \pm 0,11^{\mathrm{a}}$ & $4,32 \pm 0,10^{\mathrm{a}}$ & $4,28 \pm 0,11^{\mathrm{a}}$ \\
Intenção de Compra & $4,35 \pm 1,13^{\mathrm{a}}$ & $4,17 \pm 0,13^{\mathrm{a}}$ & $4,15 \pm 0,14^{\mathrm{a}}$ & $4,25 \pm 0,13^{\mathrm{a}}$ & $4,18 \pm 0,13^{\mathrm{a}}$ \\
\hline
\end{tabular}

Letras iguais na linha não apresentam diferença significativa pelo teste de Tukey $(p<0,05)$; EPM: Erro padrão da média; F1: padrão; F2: 4,0\% de inulina; F3: 8,0\% de inulina; F4: 12,0\% de inulina; F5: 16,0\% de inulina.

Não houve diferença significativa $(p>0,05)$ entre as formulações em nenhum atributo avaliado. Resultados semelhantes entre indivíduos adultos foram verificados por Yousaf, et $\mathrm{al}^{22}$ ao adicionar $2 \%$ de inulina em suco de banana. Conforme explicam Hauly e Moscatto ${ }^{23}$, a inulina 
é um produto amorfo, que possui aroma e sabor neutros, fato que pode explicar a semelhança entre a aceitabilidade das formulações no presente estudo.

Apesar de não ter ocorrido diferença estatística entre as amostras, durante a elaboração das geleias foi observado que conforme se aumentava o teor de inulina nos produtos, se elevava também a viscosidade. Segundo Roberfroid ${ }^{24}$, esse efeito ocorre devido à presença de grupos $\mathrm{OH}^{-}$na inulina, os quais estão disponíveis para ligação. Sua interação com a água, por ligações de hidrogênio, dificulta sua evaporação no momento da cocção da geleia, obtendo como resultado final um produto mais espesso ${ }^{25}$.

Outra modificação tecnológica observada ao longo do preparo das geleias está relacionada à cor das formulações, pois maiores concentrações de inulina promoveram uma cor mais opaca e escura nas amostras, corroborando com estudos de Volpini-Rapina, et al ${ }^{4}$, que avaliaram a adição de inulina $(6,80 \%)$ em bolos de laranja. Esse fato é causado, também, pela composição da fibra, que é um açúcar redutor, favorecendo, assim, a ocorrência da reação de Maillard, o que promove uma coloração amarela-escura ${ }^{26}$. Ressalta-se que essas modificações foram discretas e, por isso, não foram percebidas pelos provadores durante os testes sensoriais. A Figura 1 apresenta a distribuição dos provadores pelos valores hedônicos para cada atributo sensorial.

Figura 1. Distribuição dos provadores pelos valores hedônicos obtidos na avaliação da aparência, aroma, sabor, cor e aceitação global das formulações de geleias de abacaxi padrão (F1) e com adição de 4,0\% (F2), 8,0\% (F3), 12,0\% (F4) e 16,0\% (F5) de inulina. Guarapuava-PR, 2013

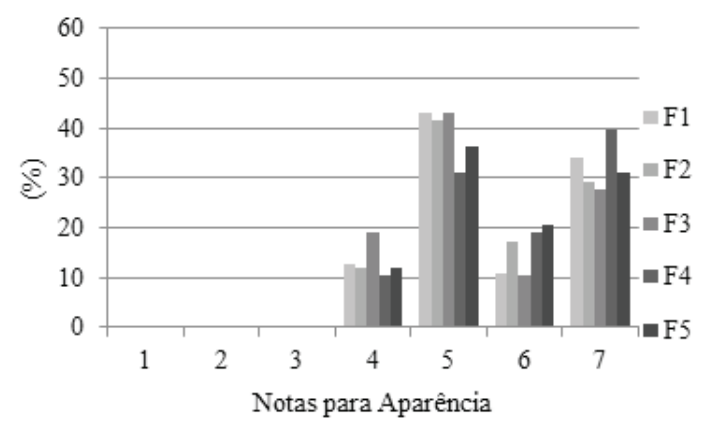

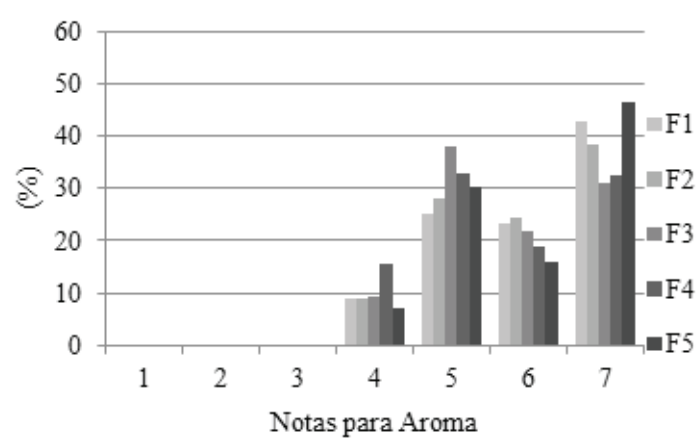
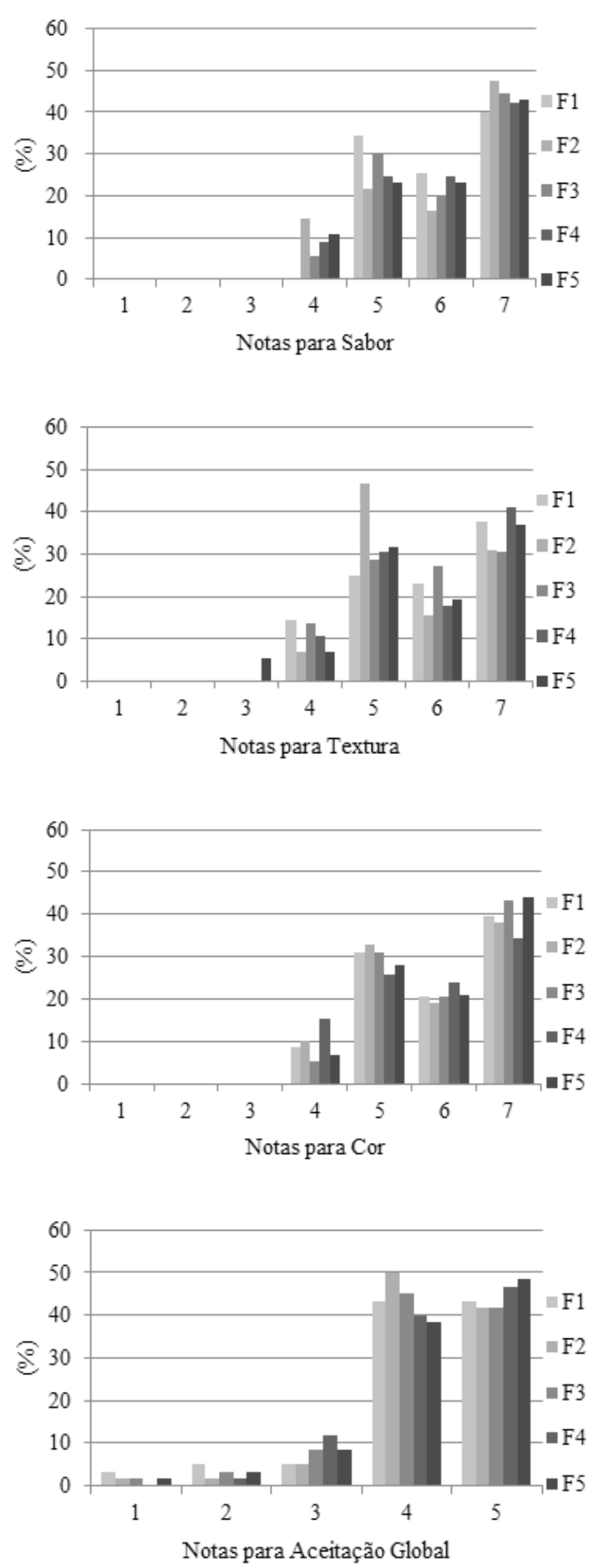
Na Figura 1, observa-se que a maioria das notas dos atributos encontram-se acima de 5 ("bom"), o que indica que as formulações, em geral, foram bem aceitas pelos julgadores. Evidencia-se que a maior frequência de notas para sabor e cor encontram-se na nota 7 ("Muito bom"), o que confirma a viabilidade mercadológica dos produtos, evidenciando sua possível comercialização, fato confirmado pelas elevadas notas de intenção de compra (Tabela 2). Efeito semelhante ocorre para o teste de aceitação global, no qual as notas se concentraram em 4 ("gostei") e 5 ("gostei muito").

A alta aceitabilidade dos produtos com adição de inulina pode contribuir favoravelmente na alimentação do público infantil, uma vez que possui inúmeros benefícios fisiológicos, tais como: a regularização do trânsito intestinal, redução dos níveis de colesterol, triglicerídeos e índice glicêmico e aumento na absorção de minerais, como cálcio e magnésio ${ }^{23}$. Esses efeitos foram confirmados por Puccio, et $\mathrm{al}^{27}$ ao adicionarem em uma fórmula infantil 90\% de galacto-oligossacarídeo e $10 \%$ de fruto-oligossacarídeo em concentração de $1 \mathrm{~g} / \mathrm{dL}$. Foi observada uma estimulação das bifidobactérias benéficas, reduzindo-se, assim, a presença de agentes patogênicos clinicamente relevantes para a flora fecal das crianças. O grupo que recebeu os prebióticos apresentou menor incidência de constipação e menor tendência de infecções do trato respiratório.

Observa-se, na Figura 2, o IA das formulações de geleia de abacaxi padrão e com adição de inulina, em relação aos atributos aparência, aroma, sabor, textura, cor e aceitação global.

Figura 2. Índice de aceitabilidade das formulações de geleia de abacaxi padrão (F1) e com adição de $4,0 \%$ (F2), $8,0 \%$ (F3), 12,0\% (F4) e 16,0\% (F5) de inulina, em relação aos atributos avaliados. Guarapuava-PR, 2013

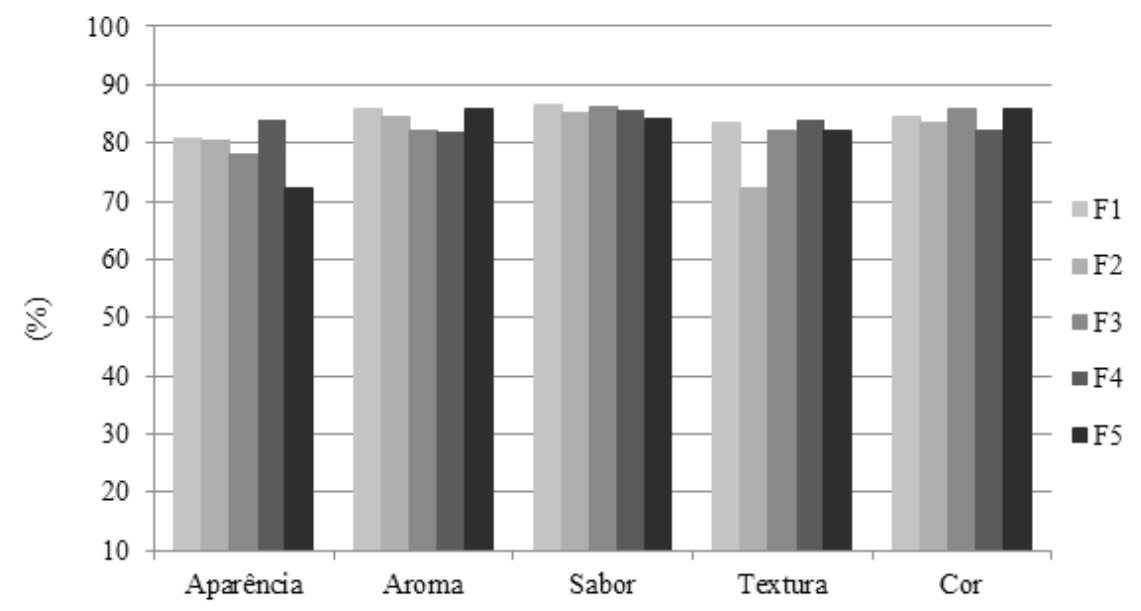

Todas as formulações apresentaram IA maiores que $70 \%$ em todos os atributos avaliados, classificando-os com boa aceitação sensorial, segundo explica Teixeira, et $\mathrm{al}^{28}$. Dados que corroboram com Silveira, et $\mathrm{al}^{5}$ ao adicionar inulina $(0,5 \%$ e $1,0 \%)$ em bebidas à base de flocos de abóbora, obtendo-se IA em torno de 73\%. Deve-se ressaltar que a boa aceitabilidade das amostras evidencia seu sucesso em uma futura comercialização. No momento da compra, a cor do produto exerce grande influência, tornando-o mais atrativo ao consumo, sendo que, geralmente, para o público infantil, cores mais fortes são associadas a maior doçura do alimento ${ }^{13}$. Também, atributos como o aroma e sabor são, provavelmente, as características mais importantes que influenciam as propriedades sensoriais de produtos alimentícios com adição de ingredientes diferenciados ${ }^{29}$. Diante disso, os altos IA observados para as geleias com adição de inulina elevam a possibilidade de compra e recompra dos produtos por influência das crianças. 
Em razão da aceitabilidade similar dos produtos, em todos os atributos e formulações, a amostra F5 (16,0\%) foi selecionada para fins de comparação, juntamente com a amostra padrão (F1), por ser aquela com o maior teor de inulina e com aceitação semelhante à padrão.

\section{Composição físico-química}

Na Tabela 3, observam-se os valores da composição físico-química da geleia de abacaxi padrão e com adição de 16\% de inulina, comparados a um produto referência.

Tabela 3. Composição físico-química e valores diários recomendados - VD* (porção média de 20 g) da geleia de abacaxi padrão (F1) e com adição de 16\% de inulina (F5), comparadas com um produto referência. Guarapuava-PR, 2013

\begin{tabular}{|c|c|c|c|c|c|}
\hline \multirow{2}{*}{ Avaliação } & \multicolumn{2}{|c|}{ F1 } & \multicolumn{2}{|l|}{ F5 } & \multirow[t]{2}{*}{ Referência** } \\
\hline & Média \pm DP & VD $(\%)^{*}$ & Média \pm DP & VD $(\%) *$ & \\
\hline Umidade (\%) & $35,54 \pm 0,10^{b}$ & ND & $37,89 \pm 0,03^{a}$ & ND & 30,47 \\
\hline Cinzas (g.100g-1)*** & $0,60 \pm 0,02^{\mathrm{a}}$ & ND & $0,61 \pm 0,01^{a}$ & ND & 0,23 \\
\hline Proteínas $\left(\mathrm{g} .100 \mathrm{~g}^{-1}\right)^{* * *}$ & $0,77 \pm 0,10^{\mathrm{a}}$ & 0,22 & $0,79 \pm 0,02^{a}$ & 0,22 & 0,37 \\
\hline Lipídios $\left(\mathrm{g} .100 \mathrm{~g}^{-1}\right)^{* * *}$ & $0,10 \pm 0,04^{a}$ & 0,02 & $0,15 \pm 0,02^{a}$ & 0,04 & 0,07 \\
\hline Carboidratos $\left(\mathrm{g} .100 \mathrm{~g}^{-1}\right)^{* * *}$ & $63,99 \pm 0,15^{a}$ & 4,68 & $60,56 \pm 0,23^{b}$ & 4,43 & 68,86 \\
\hline Calorias $\left(\mathrm{kcal}^{2} 100 \mathrm{~g}^{-1}\right)^{* * *}$ & $\begin{array}{c}266,82 \pm \\
0,89^{a}\end{array}$ & 2,66 & $211,45 \pm 0,98^{b}$ & 2,11 & 278,00 \\
\hline Fibra alimentar $\left(\mathrm{g} .100 \mathrm{~g}^{-1}\right)^{* * * *}$ & 0,35 & 0,07 & 15,52 & 3,10 & 1,10 \\
\hline
\end{tabular}

Letras diferentes na linha indicam diferença significativa pelo teste de t de student $(p<0,05)$; VD: nutrientes avaliados pela média da $\mathrm{DRI}^{21}$, com base numa dieta de 2.003,86 kcal/dia; ** Valores comparados com "geleias e compotas" ${ }^{130}$; *** Valores calculados em base úmida; **** Cálculo teórico ${ }^{11}$; DP: desvio padrão da média; ND: não disponível.

Maiores teores $(p<0,05)$ de umidade foram verificados na formulação com adição de $16 \%$ de inulina (F5). Esse fato ocorreu devido à fibra apresentar característica higroscópica, aumentando a absorção de água. Entretanto, ambas as formulações estão de acordo com a Resolução CNNPA 12 de $1978^{31}$, que estabelece o máximo de $38 \%$ de umidade em geleias de frutas. Resultados semelhantes (39,2\%) foram encontrados por Scolforo e Silva ${ }^{32}$, que avaliaram geleias de maçã com adição de fruto-oligossacarídeos $(6 \%)$.

Não houve diferença significativa entre os conteúdos de cinzas, proteínas e lipídios em ambas as amostras $(p>0,05)$, pois o açúcar e a inulina apresentam apenas traços desses nutrientes em sua composição ${ }^{11,20}$, corroborando com Scolforo e Silva ${ }^{32}$ ao adicionarem fruto-oligossacarídeos (até 10\%) em geleia de maçã.

Menores quantidades de carboidratos e calorias $(p<0,05)$ foram constatadas em F5. Esse resultado pode ser explicado, pois a inulina apresenta menores teores desses nutrientes em sua composição (97 g.100g e 1,5 $\mathrm{kcal} / \mathrm{g}$, respectivamente $)^{20}$, quando comparada ao açúcar (99,5 g.100g e 3,87 kcal/g, respectivamente ${ }^{11}$. É importante ressaltar que a geleia com adição de inulina possui um perfil de carboidratos complexos, mais benéfico para o consumo, em que $100 \%$ dos carboidratos incluem fibras alimentares ${ }^{20}$. 
Destaca-se como principal resultado desse trabalho o teor de fibras verificado na formulação da geleia de abacaxi com adição de inulina F5 (15,52 g.100g-1), expressando um aumento significativo de $4.334,28 \%$ em relação a F1. Isso se deve, principalmente, ao alto teor de fibras $(97 \%)$ presente na inulina ${ }^{17}$. Esse resultado torna o produto fonte de fibra para a faixa etária em questão, visto que a população de escolares apresenta baixa ingestão de frutas e verduras in natura, grupos de alimentos responsáveis por alto teor de fibras da dieta. Segundo Millani, et $\mathrm{al}^{33}$, o uso de oligossacarídeos pela população infantil proporciona muitos benefícios nutricionais, como a redução da ocorrência de infecções, menor incidência e prevalência de episódios de diarreia, redução do $\mathrm{pH}$ fecal, aumento da permeabilidade intestinal e melhora na absorção de cálcio.

De acordo com a Legislação Brasileira ${ }^{34}$, um produto é considerado como fonte de fibra alimentar quando apresenta em sua composição química no mínimo 3\% de fibras. Já quando o conteúdo for de $6 \%$, o alimento pode ser classificado com alto teor em fibras. Assim, pode-se considerar F5 como um produto com alto teor de fibra alimentar.

\section{CONCLUSÕES}

A elaboração dos produtos permitiu comprovar que um nível de adição de até $16 \%$ de inulina em geleia de abacaxi (redução de 100\% do açúcar) foi bem aceito pelos provadores, obtendo-se aceitação sensorial semelhante ao produto padrão. Dessa forma, esse nível de adição de inulina em geleias deve ser considerado pela indústria alimentícia, uma vez que apresenta elevados benefícios nutricionais quando consumido.

A adição de $16 \%$ de inulina em geleia de abacaxi proporcionou redução de carboidratos e calorias e aumento de umidade. Foi possível também elevar o aporte de fibras, melhorando o perfil nutricional do produto. Assim sendo, a inulina pode ser considerada um potencial ingrediente com propriedades funcionais, para adição de geleias e similares, podendo ser oferecidas aos consumidores infantis com altas expectativas de aceitação no mercado.

\section{REFERÊNCIAS}

1. Sociedade Brasileira de Pediatria. Manual de orientação para alimentação do lactente, do pré-escolar, do escolar, do adolescente e na escola. Sociedade de Pediatria. Departamento Nutrologia. 2a ed. São Paulo: SBP; 2008.120 p.

2. Costa FF, Assis MAA, Leal DB, Campos VC, Kupek E, Conde WL. Mudanças no consumo alimentar e atividade física de escolares de Florianópolis, SC, 2002 - 2007. Rev Saúde Pública. 2012 [acesso 4 Nov 2013];46(1):117-25. Disponível em: http://www.scielo.br/scielo.php?script=sci arttext\&pid=S0034-89102012000700016\&lng=pt\&nrm=is o\&tlng=en. DOI: http://dx.doi.org/10.1590/s0034-89102012005000058.

3. Amorim NFA, Schmit BAS, Rodrigues MLCF, Recine EGI, Gabriel CG. Implantação da cantina escolar saudável em escolas do Distrito Federal, Brasil. Rev Nutr. 2012 [acesso 28 Dez 2013];25(2):203-17. Disponível em: http://www.

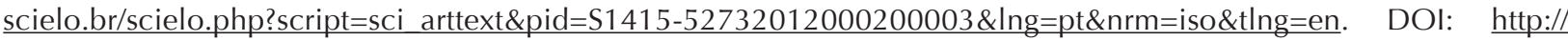
dx.doi.org/10.1590/s1415-52732012000200003.

4. Volpini-Rapina LF, Sokei FR, Conti-Silva AC. Sensory profile and preference mapping of orange cakes with addition of prebiotics inulin and oligofructose. LWT Food Sci Technol. 2012 [acesso 15 Jan 2014];48(1):37-42. Disponível em: http://www.sciencedirect.com/science/article/pii/S0023643812001156. DOI: http://dx.doi.org/10.1016/j. Iwt.2012.03.008.

5. Silveira KC, Brasil JA, Livera AVS, Salgado SM, Faro ZP, Guerra NB. Bebida à base de flocos de abóbora com inulina: características prebióticas e a aceitabilidade. Rev Nutr. 2008 [acesso 2 Jan 2014];21(3):267-76. Disponível em: http://www.scielo.br/scielo.php?script=sci arttext\&pid=S1415-52732008000300001\&lng=pt\&nrm=iso\&tlng=pt. DOI: http://dx.doi.org/10.1590/s1415-52732008000300001.

6. Rossi DM, Magalhães CRP, Kinupp V, Flôres SH. Triagem preliminar da presença de inulina em plantas alimentícias. Alim Nutr. 2011;22(2):247-50.

7. Brasil. Agência Nacional de Vigilância Sanitária. ANVISA. Resolução 16, de 30 de abril de 1999. Aprova o Regulamento Técnico de Procedimentos para Registro de Alimentos e/ou Novos Ingredientes. DOU, Brasília, 3 de dezembro de 1999. 
8. Brasil. Agência Nacional de Vigilância Sanitária. ANIVSA. Resolução 17, de 30 de abril de 1999. Aprova o Regulamento Técnico que Estabelece as Diretrizes Básicas para Avaliação de Risco e Segurança dos Alimentos. DOU, Brasília, 3 de dezembro de 1999.

9. Brasil. Agência Nacional de Vigilância Sanitária. ANVISA. Resolução 18, de 30 de abril de 1999. Aprova o Regulamento Técnico que Estabelece as Diretrizes Básicas para Análise e Comprovação de Propriedades Funcionais e ou de Saúde Alegadas em Rotulagem de Alimentos. DOU, Brasília, 3 de dezembro de 1999.

10. Brasil. Agência Nacional de Vigilância Sanitária. ANVISA. Resolução 19, de 30 de abril de 1999. Aprova o Regulamento Técnico de Procedimentos para Registro de Alimento com Alegação de Propriedades Funcionais e ou de Saúde em sua Rotulagem. DOU, Brasília, 3 de dezembro de 1999.

11. Universidade Estadual de Campinas - UNICAMP. Tabela brasileira de composição de alimentos - TACO. 4a ed. Campinas: NEPA / UNICAMP; 2011.

12. Minim VPR. Análise Sensorial: estudo com consumidores. 2a ed. Viçosa (MG): Ed. UFV; 2010.

13. Guinard JX. Sensory and consumer testing with children. Tren Food Sci Tech. 2000;11(8):273-83. DOI: http:// dx.doi.org/10.1016/s0924-2244(01)00015-2.

14. Resurreccion AVA. Consumer sensory testing for product development. Gaithersburg (MD): Aspen Publishers Inc.; 1998.

15. Monteiro CLB. Técnicas de avaliação sensorial. 2a ed. Curitiba: CEPPA-UFPR; 1984.

16. Horwitz W, Latimer Jr GW, editors. Official methods of analysis of AOAC International. 18a ed. Gaithersburg (MD): AOAC International; 2011.

17. Bligh EG, Dyer WJ. A rapid method of total lipid extraction and purification. Can J Bio Phys. 1959;37(8):911-7. DOI: http://dx.doi.org/10.1139/059-099.

18. Avanutri. Avanutri eficácia em nutrição. 2012 [acesso 28 Mar 2014]. Disponível em: http://www.avanutri.com.br/. 19. Merrill AL, Watt BK. Energy values of foods: basis and derivation. Washington (DC): USDA; 1973.

20. Beneo ${ }^{\circledR}$ HP. Product Sheet Beneo ${ }^{\circledR}$ HP, Orafti, DOC.A4-05*01/02-B. [acesso 10 Fev 2014]. Disponível em: http:// www.orafti.com.

21. National Research Council. Dietary reference intakes for energy, carbohydrate, fiber, fat, fatty acids, cholesterol, protein and amino acids (macronutrients). Washington (DC): National Academy Press; 2005.

22. Yousaf MS, Yusof S, Manap MYB, Abd-Aziz S. Storage stability of clarified banana juice fortified with inulin and oligofructose. J Food Proc Pres. 2010;34(Suppl 2):599-610. DOI: http://dx.doi.org/10.1111/j.1745-4549.2009.00419.x. 23. Hauly MCO, Moscatto JA. Inulina e Oligofrutoses: uma revisão sobre propriedades funcionais, efeito prebiótico e importância na indústria de alimentos. Semina Ciên Exatas Tecnol. 2002 [acesso 2 Nov 2013];23(1):105-18. Disponível em: http://www.uel.br/revistas/uel/index.php/semexatas/article/view/1542/1292. DOI: http://dx.doi. org/10.5433/1679-0375.2002v23n1p99.

24. Roberfroid MB. Dietary fiber, inulin, and oligofructose: a review comparing their physiological effects. Crit Rev Food Sci Nutr. 1993;33(2):103-48. DOI: http://dx.doi.org/10.1080/10408399309527616.

25. Moscatto JA, Prudêncio-Ferreira SH, Hauly MCO. Farinha de yacon e inulina como ingredientes na formulação de bolo de chocolate. Ciên Tec Alim. 2004 [acesso 5 Nov 2013];24(4):634-40. Disponível em: http://www.scielo. br/scielo.php?script=sci arttext\&pid=S0101-20612004000400026\&lng=pt\&nrm=iso\&tlng=pt. DOI: http://dx.doi. org/10.1590/s0101-20612004000400026.

26. Damodaran S, Parkin K, Fennema OR, editors. Fennema's Food Chemistry. 4a ed. Boca Raton (FL): CRC Press; 2008. 1144 p.

27. Puccio G, Cajozzo C, Meli F, Rochat F, Grathwohl D, Steenhout P. Clinical evaluation of a new starter formula for infants containing live Bifidobacterium longum BL999 and prebiotics. Nutr. 2007;23(1):1-8. DOI: http://dx.doi. org/10.1016/j.nut.2006.09.007.

28. Teixeira E, Meinert E, Barbetta PA. Análise sensorial dos Alimentos. Florianópolis: Ed. da UFSC; 1987.182 p.

29. Alamanou S, Bloukas JG, Paneras ED, Doxastakis G. Influence of protein isolate from lupin seeds (Lupinus albus ssp. Graecus) on processing and quality characteristics of frankfurters. Meat Sci. 1996;42(1):79-93. DOI: http://dx.doi. org/10.1016/0309-1740(95)00013-5.

30. Department of Agriculture. USDA. Agricultural Research Service: USDA Nutrient Database for Standard Reference; 2001.

31. Brasil. Agência Nacional de Vigilância Sanitária. ANVISA. Resolução 12, de 24 de julho de 1978. Aprova Normas Técnicas Especiais, do Estado de São Paulo, revistas pela CNNPA, relativas a alimentos (e bebidas), para efeito em todo território brasileiro. DOU, Brasília, 24 de julho de 1978 [acesso 15 Fev 2014]. Disponível em: http://portal.anvisa.gov.br/wps/wcm/connect/e57b7380474588a39266d63fbc4c6735/RESOLUCAO 121978. pdf?MOD=AJPERES. 
32. Scolforo CZ, Silva EMM. Elaboração de geleia de maçã enriquecida com fruto-oligossacarídeo. Alim Nutr. 2013;24(1):115-25.

33. Millani E, Konstantyner T, Taddei JAAC. Efeitos da utilização de prebióticos (oligossacarídeos) na saúde da criança. Rev Paul Ped. 2009;[acesso 23 Out 2013]27(4):436-46. Disponível em: http://www.scielo.br/scielo.php?script=sci arttext\&pid=S0103-05822009000400014\&Ing=pt\&nrm=iso\&tlng=pt. $\quad$ DOI: $\quad$ http://dx.doi.org/10.1590/s010305822009000400014.

34. Brasil. Ministério da Saúde. Agência Nacional de Vigilância Sanitária. ANVISA. Resolução 54, de 12 de novembro de 2012. Dispõe sobre o Regulamento Técnico sobre Informação Nutricional Complementar. DOU, Brasília, 13 de novembro de 2012 [acesso 25 Mar 2014]. Disponível em: http://portal.anvisa.gov.br/wps/wcm/connect/630a98804d 7065b981f1e1c116238c3b/Resolucao+RDC+n.+54 2012.pdf?MOD=AJPERES. 